\title{
Violências e Instituição Maternidade: uma Reflexão Feminista Decolonial ${ }^{1}$
}

\author{
Paula Rita Bacellar Gonzaga ${ }^{1}$ \\ ${ }^{1}$ Universidade Federal do Sul da Bahia, BA, Brasil.
}

\author{
Claudia Mayorga ${ }^{2}$ \\ ${ }^{2}$ Universidade Federal de Minas Gerais, MG, Brasil.
}

Resumo: A sociedade brasileira possui um histórico marcado por violências e autoritarismos. A história colonial que funda a ideia de Brasil se consolida com a noção de identidade nacional baseada em aspectos racistas, sexistas e heteronormativos. Essas violências têm sido denunciadas e visibilizadas a partir de um olhar focado na dimensão pública e macroestrutural da sociedade e as microviolências ou a dimensão da vida privada nem sempre são compreendidas como fundamentais para a reprodução dessas violências. A ideia cunhada pelas feministas dos anos 1970 de que o pessoal é político busca romper com essa divisão e reconhece que a vida privada e os aspectos que historicamente foram associados a ela, são locus fundamental para compreender como as distintas violências e sistemas de poder se entrecruzam e produzem experiências que exigem dos analistas sociais, dos atores das políticas públicas e dos sujeitos um olhar crítico fundamentado e interseccional. A proposta deste ensaio é problematizar a instituição da maternidade como um aparato patriarcal, colonial, capitalista e racista de controle e reclusão das mulheres a partir de duas construções religiosas sobre a maternidade: a primeira versão da oração Ave Maria e um itan da tradição oral iorubá sobre Oxum, orixá da fecundidade e protetora das mulheres grávidas.

Palavras-chave: Maternidade, Feminismo decolonial, Colonialidade de gênero.

\section{Violence and the Institution of Motherhood: a Decolonial Feminist Reflection}

Abstract: Brazilian society has a history marked by violence and authoritarianism. The colonial history that founds the idea of Brazil is consolidated with the notion of national identity based on racist, sexist and heteronormative aspects. These expressions of violence have been denounced and viewed from a perspective focused on the public and macro-structural dimension of society, and the expressions of micro-violence or the dimension of private life are not always understood as fundamental for the reproduction of these expressions of violence. The 1970s feminist idea that "the personal sphere" is political, seeks to break away from this division and recognizes that private life and the aspects that have historically been associated with it are a central locus for understanding how distinct violence and power systems intersect and produce experiences that require a critical and intersectional critical look from social analysts, public policy actors, and individuals. The proposal of this essay is to problematize the institution of motherhood as a patriarchal, colonial, capitalist and racist apparatus of control and reclusion of women from two religious constructions on motherhood: the first version of the Hail Mary prayer and an itan of the Yoruba oral tradition on Oxum, orixá of the fecundity and protector of the pregnant women.

Keywords: Maternity, Decolonial feminism, Gender coloniality.

\footnotetext{
${ }^{1}$ Agradecemos os apoios da Fundação de Amparo à Pesquisa do Estado de Minas Gerais (FAPEMIG) e do Conselho Nacional de Desenvolvimento Científico e Tecnológico (CNPq).
} 


\title{
Violencias y la Institución Maternidad: una Reflexión Feminista Decolonial
}

\begin{abstract}
Resumen: La sociedad brasileña tiene una historia marcada por la violencia y el autoritarismo. La historia colonial que subyace a la idea de Brasil se consolida con la noción de identidad nacional basada en aspectos racistas, sexistas y heteronormativos. Esta violencia se ha denunciado y se ha hecho visible a través de un enfoque en la dimensión pública y macro estructural de la sociedad, y la micro violencia o la dimensión de la vida privada no siempre se entienden como fundamentales para la reproducción de esta violencia. La idea acuñada por las feministas de la década de 1970 de que lo personal es político busca romper esta brecha y reconoce que la vida privada y los aspectos que históricamente se han asociado con ella son un lugar fundamental para comprender cómo se cruzan los distintos sistemas de violencia y poder y producen experiencias que requieren que los analistas sociales, los actores de políticas públicas y los sujetos tengan un ojo crítico fundamentado e interseccional. El propósito de este ensayo es problematizar la institución de la maternidad como un aparato de control y aislamiento patriarcal, colonial, capitalista y racista de las mujeres desde dos construcciones religiosas sobre la maternidad: la primera versión de la oración Ave María y un itan de la tradición oral yoruba. sobre Oxum, orixá de fertilidad y protectora de las mujeres embarazadas.
\end{abstract}

Palabras Clave: Maternidad, Feminismo decolonial, Colonialidad de género.

\section{Sobre maçãs roubadas, correntes que brilham e águas revoltas}

A sociedade brasileira possui um histórico marcado por violências e autoritarismos. A história colonial que funda a ideia de Brasil se consolida com a noção de identidade nacional baseada em aspectos racistas, sexistas e heteronormativos (Mayorga, 2011). Nos aspectos macro e microssociais, essas dinâmicas excludentes terminam por constituir, de forma violenta, práticas, discursos e subjetividades baseadas na hierarquização e na desumanização de determinadas experiências. Essas violências têm sido denunciadas e visibilizadas a partir de um olhar focado na dimensão pública e macroestrutural da sociedade e as microviolências ou a dimensão da vida privada nem sempre são compreendidas como fundamentais para a reprodução dessas violências.

A ideia cunhada pelas feministas dos anos 1970 de que o pessoal é político (Hanisch, 1971) busca romper com essa divisão, e reconhece que a vida privada e os aspectos que historicamente foram associados a ela são locus fundamental para compreender como as distintas violências e sistemas de poder se entrecruzam e produzem experiências que exigem dos analistas sociais, dos atores das políticas públicas e dos sujeitos um olhar crítico fundamentado e interseccional. Um desses aspectos é a ideia de maternidade, criticada pela teoria feminista, como uma das instituições patriarcais por excelência.

Que é ser mãe? O que significa termos um potencial biológico como condição mínima de pertencimento identitário? Ser mulher é ser mãe? E as mulheres que não são mães; o que são? Como é possível recusar o papel que produz respeitabilidade no sistema patriarcal? Como a obrigatoriedade do cuidado com a prole tem sido útil para a manutenção das mulheres no ambiente doméstico, mesmo quando ocupam funções no mundo público? Se a maternidade redimiria as mulheres do pecado original, aquelas que a recusam estariam negando essa redenção?

Até mesmo algumas perspectivas feministas têm produzido discursos que reificam a mulher-mãe como uma versão completa de si e as mulheres não-mães como pessoas em amadurecimento, em negação ou como aquelas que não tiveram chance de realizar esse intento. Entre todos os mitos que o patriarcado criou sobre as mulheres, não seria a maternidade aquele em que mais efetivamente acreditamos, vivenciamos, defendemos e reproduzimos? Como falar de mulheres que optaram pela não maternidade, sem citar a maternidade? Como falar sobre mulheres se tornou algo naturalmente associado à maternidade? Ao referirmo-nos a homens adultos em idade fértil que não tem filhos é necessário sinalizar que eles são homens 
não pais? Mãe é um significante presumido da palavra mulher, tornando aquelas que não são mães, estrangeiras no próprio substantivo que as nomeia, que reduz um rol de experiências generificadas à presença ou ausência da prole; estrangeiras em seus próprios corpos, definidos como fontes obrigatórias de vida.

Mulheres que decidem não ter filhos são figuras ininteligíveis e é necessário perguntar o porquê da recusa da maternidade provoca tanto incômodo. A proposta desse ensaio é problematizar a instituição da maternidade como um aparato patriarcal, colonial, capitalista e racista de controle e reclusão das mulheres. Uma das tantas violências que marcam a sociedade brasileira. É fundamental destacar que não se trata da potencialidade reprodutiva, nem tampouco da relação possível entre mulher-filha/ filho, mas sim da maternidade como instituição que se constitui como prerrogativa de existência legítima para as mulheres. Ser mãe é socialmente apontado como objetivo-fim para a vida feminina e sendo desse modo, as mulheres são correntemente lidas como incompletas. A maternidade é o destino possível para que se justifique a existência desses corpos não fálicos em uma sociedade patriarcal; é o que confere às mulheres algum valor. Nessa equação, a mulher é o meio para um fim: a descendência.

O caráter fictício da categoria mulher e como a construção desta foi fundamental para o sucesso do estado colonial (Lugones, 2014) nos levam a examinar como ser mãe é uma identidade ficcional a partir da qual naturalizamos as mulheres no âmbito do cuidado e da abnegação. Existem outras possibilidades de maternidade que não implicam numa postura de autosacrifício compensador? Por que a maternidade segue sendo um argumento legítimo para justificar que mulheres suportem a fome, a miséria, a violência, a desistência dos sonhos e de ambições individuais? Quão conveniente é ao patriarcado que as mulheres estejam convencidas de que a maternidade é um destino natural inegável?

Pensar a maternidade como um destino definido na biologia dos corpos é insustentável quando pensamos a conjuntura que cerca dois aspectos centrais dessa experiência: o primeiro consiste na suposta ideia de liberdade de escolha pela maternidade; o segundo, na condição de constante produção de discursos e práticas de repressão e rechaço às mulheres que recusam a maternidade. Em outras palavras, não é possível falar de maternidade a partir de uma refe- rencial individualizante, mas a partir de uma perspectiva sócio-histórica.

Sobre a pressuposta liberdade de escolha pela maternidade, Badinter (2011) aponta que esta pode ser, de fato, um embuste. A autora problematiza que tal escolha é cotidianamente cobrada pela família, pelas amigas, estimulada pelo Estado e pela Igreja, que são instituições originalmente natalistas e que operam discursivamente para regular a sexualidade e a capacidade reprodutiva das mulheres, que, muitas vezes, aceitam cumprir o papel de mãe mesmo sem ter certeza de que realmente desejam fazê-lo. Quando refletem sobre suas experiências de não-maternidade, as cientistas sociais e feministas Anzorena e Yañez (2013) identificam como a maternidade sempre pareceu um destino inevitável, mesmo na infância e adolescência, quando elas começaram a pensar que não gostariam de ser mães. Essa leitura já foi denunciada desde a década de 1940 na obra de Beauvoir (1980), que aponta que a maternidade é possivelmente o instrumento mais eficaz da subjugação feminina, visto que esse não se fazia através da violência explícita e sim pelo convencimento de que o melhor que a mulher podia fazer era ser mãe. Logo, a maternidade é um discurso que naturaliza a própria violência na qual se baseia, o que se explicita na repressão e rechaço às posições críticas à maternidade e às resistências.

O Estado cumpre um papel fundamental para institucionalizar o caráter compulsório da maternidade. O tabu que cerca o aborto, por exemplo, é um fenômeno sociológico centrado na obrigatoriedade da maternidade, na moral social que, além da culpa cristã, submete as mulheres que subvertem a principal norma do seu gênero à penalização jurídica (Beauvoir, 1980). No Brasil, a legislação vigente limita a esterilização voluntária a pessoas com pelo menos dois filhos vivos ou com mais que vinte e cinco anos. A outra condição é a autorização do cônjuge (Lei No 9.263, 1996). Apesar de essas regras se estenderem a homens e mulheres, é efetivo que em um país onde o ônus da contracepção e do cuidado parental recai sobre as mulheres, é sobre o corpo feminino que essas interdições são produzidas. Sobre essa dupla função de controle dos corpos e produção de subjetividade:

O Estado tem duas fontes principais de poder sobre as mulheres. Regula o acesso à base material da procriação, isto é, legisla sobre a contracepção, o aborto e a tecnologia do parto, deci- 
dindo quem terá permissão para os mesmos, como e quando. E o Estado tenta controlar as mentes mistificando os fatos a esse respeito. Por exemplo, parece que são as mulheres que tomam decisões reprodutivas independentes, pelas quais se sentem individualmente responsáveis; afinal, são adultos "individualizados". Mas, por estarem "em relação" com o Estado, suas decisões já foram tomadas por elas, através de leis restringindo sua sexualidade, suas escolhas reprodutivas e seu acesso a empregos (Dimen, 1997, p. 53).

Anzorena e Yañez (2013) afirmam que a possibilidade de não parir e não gerar é uma condição primária para que possamos pensar em maternidade voluntária. Enquanto aborto for crime moral e penal, enquanto a recusa pela maternidade for considerada um sintoma de perturbação ou de deficiência, a maternidade continuará sendo uma função prescrita para as mulheres e da qual estamos constantemente sendo impelidas a exercer.

A chamada segunda onda do feminismo reivindicou o direito ao corpo em sua amplitude (sexualidade, autonomia, reprodução) e as mulheres latino-americanas vivenciam até os dias atuais a supressão desses direitos através de discursos simbióticos de feminilidade e maternidade e de manutenção da noção hegemônica de família tradicional. Esse descompasso impõe sobre a mulher o peso da obrigatoriedade do exercício desse papel de mãe/esposa como primordiais, mesmo quando elas já estão ocupando espaços de trabalho, política e ciência. Swan (2007) discorre sobre a conexão entre a sexualidade e a reprodução, o modo como uma função orgânica entre elas foi imbuída de significados sociais e cargas simbólicas a ponto de ter se tornado o centro da existência feminina e, por extensão, o fundamento de um modelo de família que é a gênese da estrutura patriarcal. A manutenção de representações deterministas que diminuem e objetificam as mulheres, reduzindo-as a seres naturais e biologicamente programados para funções relativas ao sexo e a procriação. Tal reducionismo segue sendo um exercício legitimado e regulado pelo Estado por meio do qual os corpos das mulheres são abordados como fontes públicas de produção humana.

Badinter (2011) aborda a contemporaneidade da discussão, considerando como o movimento ecológico atualmente tem papel fundamental no reavivamento do discurso naturalizante, o qual adota a pers- pectiva da fêmea que naturalmente está programada para a reprodução em detrimento da mulher, sujeito histórico, social e psicológico dotado de interesses e aptidões que podem destoar do que é pré-estabelecido. Essa redução das mulheres a uma função corpórea é uma realidade que se confunde entre discursos conservadores e de algumas correntes feministas. Afinal, o que nos faz mulheres?

\section{Me aterra pensar en convertirme en un cuerpo arrojado a la vulnerabilidad, para que otrxs inter- vengan en él y decidan qué es mejor (siempre en función de el/la bebé) sin consultarme ni respetar mis decisiones. Me espanta la idea de la materni- dad biológica como una entrega de mi cuerpo que se escape de mi control (Anzorena, \& Yañez, 2013, p. 231).}

A naturalização da procriação como função intrínseca à construção da identidade das mulheres tem efeitos paradoxais na alocação das mulheres na estrutura patriarcal. Negar a maternidade não é uma possibilidade legitima. Contudo, ainda que a maternidade seja uma experiência sacralizada, as mulheres mães não são alavancadas a condição de sujeito. "Louvada como apanágio das mulheres, a capacidade de procriação tem, por outro lado, o peso de um destino, uma fatalidade que definiria as mulheres enquanto a verdadeira mulher" (Swan, 2007, p. 203). A distinção da maternidade como atributo que confere legitimidade a mulher confere efeitos de distinção intragênero, sendo aquela que se destaca entre as outras, responsável por lidar com essa função solitariamente.

É necessário, no entanto, identificar que por mais que uma mulher nunca tenha sido mãe, a maternidade, enquanto instituição, faz parte da constituição de sua subjetividade. A maternidade é uma instituição que nos antecede e para qual a sociedade nos molda. Por mais que não se tenha vivido a maternidade ela é estranhamente próxima, mesmo quando a negamos; ao mesmo tempo que ela impõe uma hierarquia entre as mulheres: não ser mãe é estar a margem de um conjunto de atribuições, preocupações, prazeres e compromissos que a tal experiência implica. Nesse sentido, corpos femininos são socialmente lidos como mães em potencial, mesmo que não desejem a maternidade. É uma posição paradoxal: mesmo recusando a maternidade, as mulheres continuam sendo definidas por ela, ou pela sua ausência: “No podía salir de 
mi asombro: todo lo que yo decía era tomado como pasajero. Al final lo logré, desvalorizada en mi decisión, infantilizada, conseguí que se respetara mi decisión" (Anzorena, \& Yañez, 2014, p. 230).

É fundamental explicitar como a naturalização da maternidade institucionalizada, compulsória e hierarquizante produz efeitos reducionistas e nocivos para as mulheres. Partindo das considerações sobre escolha, controle estatal e produção de subjetividade, apresentaremos reflexões sobre a construção da noção de maternidade como instituição que transcende a função reprodutiva, organiza, hierarquiza e confere valor às mulheres no sistema de gênero colonial moderno, fazendo com que a violência desse processo seja compreendida como natural e necessária. Em sua crítica, Lugones (2014) expõe que a construção do dimorfismo sexual, da heterossexualidade e do gênero como realidades biológicas e complementares foi fundamental para o projeto colonial. A categoria mulher, portanto, não é menos fictícia do que a categoria raça. Considerando ainda que colonialidade é, além de classificação racial de indivíduos, um sistema de imposição de todos os campos da vida humana, educação, cultura, economia, linguagem, política, religião e modos de vida refletimos como a instituição da maternidade é uma imposição colonial naturalizada e que tem efeitos de contenção e controle das mulheres.

Analisamos o modelo de maternidade institucionalizado a partir de duas figuras principais, sendo uma oriunda do cristianismo e outra do candomblé: a Virgem Maria e Oxum. A escolha pela primeira se justifica pela função que o cristianismo desempenhou na consolidação do sistema de gênero colonial moderno, sendo a Igreja Católica responsável pela regulação da sexualidade e da reprodução dos indivíduos no período do Brasil Colônia (Del Priori, 1994). Justifica-se também por apresentar grande atuação em prol de retrocessos no campo dos direitos sexuais e reprodutivos das mulheres por meio de vinculação de representantes religiosos a partidos políticos na América Latina (Ruibal, 2014).

A segunda escolha surge a partir da retomada que Lugones (2014) faz da produção de Oyéronké Oyewúmi. A autora defende que a divisão binária do gênero e a categoria mulher, não eram princípios organizadores da sociedade yoruba até a coloniza- ção. O candomblé é uma religião de matriz africana, presente entre os yorubás e Oxum é uma das Orixás mais cultuadas no Brasil, em Cuba e no Haiti, países marcados pela presença de populações negras. No sincretismo religioso é associada à Nossa Senhora da Conceição e Nossa Senhora das Candeias, ambas retratadas como referências a Maria.

Considerando a posicionalidade dessas escolhas e as contribuições do feminismo decolonial, questionamos se existem outros modos de abordar a maternidade que não como uma inscrição natural que toda mulher carrega em si. A partir da provocação de que a categoria mulher é uma categoria racista, visto que originalmente não incluía as mulheres negras (Lugones, 2014), buscamos examinar a maternidade como instituição colonial, produzida pelo sistema de gênero colonial moderno. Historicamente narrada como natural e homogênea a maternidade é tomada como experiência universal por meio da história de um corpo dócil que chegou ao seu destino. Ao apontar que a criação de verdades é um privilégio dos colonizadores, Jimenez-Lucena (2014) faz pensar porque acreditamos tanto na maternidade como uma verdade universal se efetivamente ela é uma instituição politicamente organizada, cientificamente reificada e explorada e juridicamente controlada.

\section{A instituição da maternidade como redenção}

Theotokos virgem, regozija, Maria cheia em graça, o Senhor é contigo. Bendita és entre as mulheres e bendito é o fruto de teu ventre, pois portas o Salvador de nossas almas. (Trecho da Oração Ave Maria, versão bizantina²)

Os versos acima são a tradução da oração Ave Maria em sua versão bizantina, a mais antiga de que se tem conhecimento. Cinco versos que apresentam não apenas égides da Igreja Católica - a virgem que engravida do Senhor, o filho bendito de Deus já denominado de Salvador no momento da concepção e a onipresença, onipotência e onisciência de Deus - mas égides do próprio patriarcado - a mulher mãe valorizada entre as outras, mas que só se distingue por executar seu papel nos planos do Senhor. Ou seja, ela não é valorizada por si, mas sua distinção é posicio-

\footnotetext{
${ }^{2}$ Uma versão dessa oração está disponível no site: http://oracoesesalmos.com/oracao-ave-maria/
} 
nada entre as mulheres enquanto o fruto de seu ventre bendito. A vigilância tutelar da figura masculina que está com ela, a definição do Salvador que é o fim para o qual o ventre materno é apenas um meio e a hierarquização das mulheres são aspectos apresentados pela eleição daquela que aceita gerar o herdeiro e que será denominada virgem.

Qual a função da personagem Maria nesse enredo? Que papel ela cumpre ao aceitar ser mãe do filho de deus sobre todas as coisas? Uma pista para essas perguntas pode estar na primeira palavra dessa oração, Theotokos é o título que a Igreja Ortodoxa atribui a Maria, significa Portadora de Deus ou A que deu luz a Deus. A função de Maria, personagem feminina mais conhecida da Bíblia cristã é portar o filho de deus, dar à luz a ele. Maria é um ventre a serviço de um plano que não construiu, que não a inclui em sua totalidade e do qual não será a protagonista. A história de Maria não é sobre ela, mas sim sobre seu bendito ventre.

Remeter a uma oração advinda de trechos do Antigo Testamento pode parecer aleatório, ou até mesmo provocativo, mas de fato é fundamental para que possamos compreender qual a mensagem que se elabora a partir da instauração e imposição do cristianismo nos países latino-americanos. Efeitos cumulativos da religião cristã produziram inúmeros tabus sobre o corpo e a sexualidade feminina, a impureza atribuída à vagina e ao sangue menstrual confeririam um caráter menos humano às mulheres e possibilitaram uma constante renovação da culpa como reguladora de suas subjetividades (Millet, 1970/2000). A imposição de um deus masculino, onipresente, onisciente e onipotente que para satisfação de seus planos escolhe uma mulher, a engravida e a convence de que a maior honra da sua vida é carregar o seu filho é uma narrativa carregada de signos, inclusive a possibilidade de redenção da mulher, até então a responsável pelo pecado original, pela via da maternidade.

A instituição da maternidade assim se consolida como uma das égides do modelo patriarcal moderno colonial cristão e que se sustenta não apenas por iniciativas repressoras e violentas (criminalização do aborto e da contracepção, controle estatal da natalidade, punição simbólica e física de mulheres inférteis, casamentos forçados, violência sexual), mas que, principalmente, está sustentada por discursos de poder produtivos que valorizam, centralizam, reduzem e hierarquizam as mulheres pela adequação que elas apresentam ao modelo de maternidade ideal, abnegado e incondicional que é apresentado como possibilidade de redenção.

A figura de Maria é recorrentemente retomada para lembrar as mulheres desse modelo. Representantes cristãos são os maiores defensores da criminalização total do aborto em países latino latino-americanos, dificultando o avanço da pauta a partir de argumentos religiosos (Ruibal, 2014). No Brasil, o movimento conservador defende que a mulher se torna mãe no mesmo momento da criação do concepto, tal como a anunciação à Virgem Maria, cabe à mulher a aceitar a criação da vida como exterior a sua vontade ou à sua participação, mesmo nos casos onde a gravidez seja fruto de estupro (Machado, 2010). Assim, a maternidade redireciona as mulheres a seu atrelamento inevitável com a natureza. Todas as subversões são possíveis, desde que se mantenha vívida a noção de que somos, antes de tudo, corpos reprodutores, amas de leite, mães - - corpos incapazes de se autodeterminar.

Como Lerner (1990) aponta, essa capacidade reprodutiva foi alvo de uma das primeiras situações de exploração da sexualidade femininfeminina, a obrigação de reproduzir. Enquanto o desenvolvimento masculino era classificado complexamente, com diversas fases, as mulheres poderiam mudar apenas da condição de filha para esposa o que se consolidava com a produção de descendentes. A obrigação com a procriação delimitava o valor das mulheres devido à sua capacidade reprodutiva, escravizando seus corpos como produtores de novos cidadãos e limitando-as a peças substituíveis no âmbito familiar. No entanto, essa exploração não se deu de forma homogênea. A colonização e posteriormente o sequestro e escravização de pessoas trazidas do continente africano implicaram em imposição de valores, modos de vida, crenças e classificação racial. A abnegação e submissão feminina previstas para as mulheres europeias não era viável para as mulheres indígenas e negras, consideradas como não humanas, bestiais, inferiores. Elas não cabiam na figura imaginária da virgem que aceita seu destino.

"La imagen de Jezebel se originó en tiempos de la esclavitud cuando las negras eran pintadas, en las palabras de Jewelle Gomez, como "nodrizas sexualmente agresivas". La función que el estereotipo de la Jezebel cumplió fue relegar a todas las negras 
a la categoría de mujeres sexualmente agresivas, proveyendo una justificación poderosa para la proliferación de la violación sexual por hombres blancos relatada por relatadapor las esclavas negras. Pero Jezebel cumplió otra función. Si se podía pintar a las esclavas negras como poseedoras de apetitos sexuales excesivos, el incremento de la fertilidad debería ser el resultado esperado. Al suprimir el cuidado que las mujeres afro-americanas podrían haber brindado a sus propios niños/ as, lo que habría fortalecido las redes de la familia negra, y al forzar a las esclavas negras al trabajo en plantaciones, a ser nodrizas para los hijos de los blancos, y a nutrir emocionalmente a sus dueños blancos, los propietarios de los esclavos lograron conectar eficazmente, las imágenes predominantes de la Jezebel y de la mammy con la explotación económica inherente en la institución de la esclavitud." (Lugones, 2014, Pp. 38-39).

Coube às negras e indígenas o encargo de serem associadas ao pecado, impureza, bestialidade e demonização, o que justificou que o modelo colonial e cristão se baseasse na violação sistemática desses corpos femininos não brancos. Nesse continuum discursivo, o estupro colonial foi legitimado e a retirada ou imposição da maternidade passou a ser um instrumento usual no controle da sexualidade e da capacidade reprodutiva dessas mulheres. As mulheres negras que engravidavam em situação de escravidão eram obrigadas a manter o ritmo de trabalho nas lavouras e o fruto das gestações eram, inevitavelmente, considerados propriedades do senhor da casa grande. Nesse sentido a maternidade era negada às mulheres negras, pois não eram vistas como mulheres. Logo, não poderiam ser mães de seus filhos. No entanto, assim como elas não poderiam decidir sobre o uso do leite materno que produziam quando engravidavam, seu corpo e todos os seus recursos eram apropriados pelo senhor, inclusive o cuidado maternal que passou a ser benefício das crianças brancas. Como aponta Mott (1989), era recorrente que as mulheres negras recorressem ao aborto e ao infanticídio como estratégia de resistência ao uso do seu corpo em benefício dos senhores e também como modo de se proteger dos sofrimentos de se levar a termo uma gravidez em contexto de escravidão.

Nesse sentido existe uma distinção fundamental para se compreender que a imposição da mater- nidade é flagrantemente trespassada pela questão racial. Como aponta Carby (1989) "Dar à luz (sem ser livre) ao herdeiro da propriedade não é a mesma coisa que dar à luz (sem ser livre) à propriedade". Ainda que a maternidade seja uma imposição para mulheres brancas e negras, a hierarquização desses corpos a partir do pensamento eurocentrado colonial irá definir posições distintas para ambas. No caso das mulheres negras lhes coube o papel da mãe preta, único papel que gerava respeitabilidade e algum reconhecimento (Gonzalez, 1983). O lugar do cuidado imposto pelo gênero a elas precisa ser ressignificado a partir da raça, pois deverão exercer práticas pela obrigação de serem mulheres, sem nada em troca, por serem negras escravas. Nesse sentido é que se cria uma ideia de mulher negra disposta a reconquistar a maternidade outrora roubada. Mas qual maternidade é possível para as mulheres negras?

O controle dos corpos das mulheres negras ocorre pela imposição da maternidade compulsória, mas a maternidade dedicada a crianças brancas, de classe média; a maternidade legitimada para a mulher negra no Brasil é a que está vinculada a exploração violenta do trabalho doméstico. As experiências de maternidade que perpassam pelos corpos negros estão marcadas por inúmeras estratégias estatais de dizimação desse grupo, como se constata com os inúmeros casos de mortes evitáveis de mulheres negras em assuntos relativos a saúde sexual reprodutiva. Werneck (2014, pp. 7-8) evidencia como a partir da segunda metade do século XX o avanço tecnológico proporcionou a esterilização compulsória e massiva das mulheres negras. Na defesa de ideologias mascaradas de ciência, muitos mitos foram defendidos em detrimento dos direitos das mulheres envolvidas. O caráter eugênico e racista que permeou a esterilização compulsória de mulheres negras, no Brasil e nos Estados Unidos, sob o pretexto do controle da natalidade segue sem esclarecimentos Estados envolvidos.

Essa realidade não se modificou tanto quando consideramos que em recente levantamento do Ministério da Saúde as mulheres negras são 60\% das que morrem no parto, destaque para o fato de que a mortalidade materna é evitável em $90 \%$ dos casos, de acordo com a Organização Mundial de Saúde. A Articulação de Mulheres Negras Brasileiras (2015, pp. 36-40), em 40), em publicação referente à Saúde das Mulheres Negras, sinaliza que a discrepância entre mulheres brancas e não brancas nos casos de 
mortalidade materna se estende também aos casos registrados como aborto e àqueles como hemorragias e infecções, os quais podem ser consequências de abortos inseguros que não foram devidamente atendidos e notificados. Essa conjuntura indica que o racismo dos discursos dominantes, violentos e autoritários, continua se validando como cientificocientífico para defender processos de eugenia que operam por inúmeras vias. Situação que se repete nos casos de aborto. Uma mulher negra tem três vezes mais probabilidade de morrer durante um aborto provocado que uma mulher branca no Brasil.

Jimenez-Lucena (2014) denuncia como o corpo das mulheres marroquies foram territórios de investimento do discurso cientifico científico colonial, sob argumentos de orientação, proteção, adequação e normatização, os agentes do estado se arvoraram sobre esses corpos e produziram evidências que foram admitidas como cientificas científicas e que seguem reverberando na manutenção dos corpos femininos não brancos como realidades limitadas a corporeidade e não como sujeitos sócio-políticos. Essa realidade se aproxima da experiência de colonização dos corpos de mulheres negras e indígenas na América Latina, onde a reprodução tem se caracterizado como campo minado.

Lugones (2014) e Jimenez-Lucena (2014) apontam ainda que a efetividade do sistema de gênero colonial/ moderno implica inclusive em um acordo tácito de solidariedade entre homens colonizados e colonizadores no que tange a redução das mulheres não brancas. Nesse sentido, retomamos o argumento do Movimento Negro sobre a esterilização compulsória ser um problema de violência racista e sexista porque rompia com a função política das mulheres negras de gerar, de produzir descendentes. Diante disso, segue o questionamento sobre quão livre estamos se seguem considerando que nossa função política é novamente uma função biológica baseada na nossa sexualidade e capacidade reprodutiva. Anzorena e Yañez (2013) denunciam que também o discurso feminista passou por uma re-institucionalização da maternidade. De acordo com as autoras, ao tentar incluir experiências de mulheres não representadas no modelo de mulher do feminismo hegemônico, o movimento feminista acabou produzindo uma exaltação da mãe pobre e solteira que tudo suporta em nome da criação de seus filhos.
Isso traz novos problemas. O primeiro é que, novamente, se fala da maternidade da mulher negra como uma função que ela suportará apesar de qualquer dificuldade ou problema. O sofrimento de outrora ligado à escravidão agora será imposto pela desigualdade econômica, o racismo institucional, a violência obstétrica e o genocídio da juventude negra que mata jovens e interrompe o projeto de maternidade de mulheres que socialmente não são autorizadas a declinarem de exercer.

Nesse sentido é necessário escutar o que dizem as mulheres negras sobre como tem sido sua experiência de maternidade. A maternidade outsider with in em famílias brancas, a maternidade roubada pelos agentes do estado, a maternidade compartilhada, a maternidade interrompida, a maternidade desejada ou não desejada. É preciso que se escute, por exemplo, quando diante da redução de suas potencialidades para a reprodução, as militantes do Movimento Negro Unificado de Belo Horizonte e o grupo Geledés pautaram que os direitos reprodutivos deviam ser respeitados a partir do que as mulheres negras desejassem e não do que se prescrevia como função para elas (Damasco, Maio, \& Monteiro, 2012).

Vale considerar que essa valorização central da maternidade acaba por produzir, mais uma vez, uma hierarquização entre as mulheres no próprio feminismo e no acesso aos direitos. Tlostanova (2014) aponta que o processo de colonização que ocorreu no Cáucaso e na Ásia Central, assim como o que ocorreu nas américas e no continente africano, produziu uma discriminação heterogênea contra as mulheres, onde ao longo da vida a mulher gozaria de níveis distintos de respeito e participação política, sendo que jovens esposas sem filhos não seriam beneficiárias de direitos garantidos exclusivamente às mulheres mães de família com esposa e netos. Essa realidade também aparece no trabalho de Anzorena e Yañez (2013), que apontam que esse tipo de categorização reforça a centralidade de políticas sociais que só apoiam as mulheres quando isso implicar em mantê-las na tarefa de cuidado das crianças. Considerando a realidade brasileira o Programa Criança Feliz ${ }^{3}$, lançado pelo governo federal em 2016, se tornou um exemplo de como o estado continua se eximindo dos cuidados na primeira infância e continua ocupando um lugar

${ }^{3}$ Os principais objetivos e princípios do Programa Criança Feliz estão disponíveis no site do governo federal brasileiro: http://calendariobolsafamilia2015.com.br/programa-crianca-feliz/. 
de fiscal do exercício da boa maternidade feminina em nome do desenvolvimento saudável das crianças.

"La política sanitaria colonial intervino en la configuración de las relaciones de género de muchas maneras: universalizando un modelo "ideal"' de mujer, exaltando las relaciones de género occidentales como algo realmente extraordinario frente a las “orientales' orientales" y también manteniendo la subordinación de las mujeres en los ámbitos profesionales y personales" (Jimenez-Lucena, 2014, Pp. 54).

As estratégias coloniais de intervenção do estadoEstado, a partir de discursos disciplinares de poder, higiene e normatização da vida, são acirradas em momentos de retrocessos políticos e implantação de regimes conservadores, totalitários ou ditatoriais (Scott, 1990) contra os corpos e os direitos das mulheres. A redução de creches, de acesso a contraceptivos e a aborto legal e seguro, assim como o fortalecimento de discursos natalistas e moralizantes cumprem com a função de lembrar as mulheres de que sua principal função se dá na criação dos filhos; reduzindo ou retirando a participação destas no mercado de trabalho, espaços de decisão e organização política e produção de conhecimento (Scott, 1990).

Qual a possibilidade de viver a maternidade fora das prescrições e controles estabelecidos pelas normas sociais, religiosas, jurídicas e cientificascientíficas? É possível viver a maternidade sem que isso implique na sobrecarga da mulher e na abdicação de suas ambições individuais ou em sua sobrevivência individual? Quando recusar a maternidade pode ser uma estratégia de ressignificação de si e da identidade de mulher? Qual potencial de reorganização econômica e política está implícito num questionamento dos fundamentos da maternidade como verdade norteadora da vida das mulheres? Pode a recusa pela maternidade ser uma possibilidade de descolonização dos nossos corpos?

\section{A mulher no espelho e a determinação de si}

Obatalá reuniu todos os “"Oborós”", as divindades masculinas e com estes deuses ele fez uma sociedade de Orisás.
Osun ficou muito ofendida e foi até eles e perguntou: “"Eu também sou Orisá, porque me excluem?"?"

Todos os Oborós riram e disseram: ““Desde quando precisamos de mulheres? Não está a nossa altura” Osun então entendeu que não precisavam dela, e retirou o seu Asé do mundo. Não havia mais fertilidade, as mulheres não engravidavam, a água não matava mais a sede e a natureza secou. Os Oborós foram reclamar a Olodumaré, queriam que ele obrigasse Osun a dar seu Asé novamente, Mas Olodumaré disse:

“"Vocês disseram a Osun que ela não é importante e agora sofrem sem ela. Devem desfazer esse erro"

Todos os homens foram as margens de Rio Osun e levaram oferendas a Ayabá que logo surgiu das águas e perguntou:

"Por que estão chamando meu nome se eu claramente não estou a altura de vocês?"?"

Osun fez com que os homens implorassem seu retorno, e então ela aceitou voltar, mas com a condição que ela e as Ayabás também tivessem voz ativa entre os Orisás.

E assim foi, a terra voltou a prosperar e Osun foi chamada Iyalodê, a mulher honrada.

Osun Ominibú é a Osun líder, a grande senhora que quando fala todos se abaixam.

Ore Yeye

(Itan, Tradição oral Yorubá4)

A epígrafe acima pode ser lida como outra interpretação possível da capacidade reprodutiva e da função da maternidade na vida das mulheres. Ao ser excluída de um espaço decisório por ser mulher, Oxum, orixá da fecundidade, retira seu axé do mundo. Tudo que é regido por sua energia não avança, rompendo com a ideia da mãe abnegada que se sacrifica em nome do bem comum. Oxum não aceita ser diminuída ou excluída por ser mulher, ela seca os rios, as plantações e os ventres. É preciso respeitar e reconhecer seu poder para que ela faça $o$ mundo fértil novamente. Nesse sentido, a potencia-

\footnotetext{
${ }^{4}$ Uma versão desse Itan pode ser encontrado em: http://omilayo.blogspot.com/p/orisas.html Itans tradicionalmente são histórias transmitidas oralmente, sem autoria definida, e remontam à transmissão ancestral da tradição ioruba pela oralidade.
} 
lidade da reprodução se dá de outra forma, ao secar o mundo Oxum resiste a sujeição de suas funções ao poderio masculino. Ela é quem rege a maternidade, não o contrário, ela não está acorrentada a essa função como um destino inevitável, ela é senhora do seu corpo e de suas capacidades.

Quando os demais orixás masculinos solicitam que Olodumaré a obrigue a tornar o mundo fértil novamente entramos em contato com uma divindade superior que não se impõe a Oxum, seu corpo e seu axé não são violáveis por serem ligados ao feminino. Essa perspectiva rompe com uma noção largamente vinculada da mulher como extensão do território a ser dominado e explorado. Na América Latina, a colonização se deu também pela exploração de mulheres indígenas e negras. No caso do Brasil, a construção do mito da democracia racial, pautado na proposição da miscigenação como uma mistura pacificapacífica entre as três raças, esconde a exploração sexual imposta às mulheres não-brancas. Nesse itan, não apenas a maternidade não é uma obrigação do feminino, como a violação não é um pressuposto legítimo ao masculino. Não seriam, então, ambos desdobramentos da criação da mulher como categoria que define e restringe corpos sexuados como violáveis e reprodutores?

"La emergencia de la mujer como una categoría reconocible, definida anatómicamente y subordinada al hombre en todo tipo de situación, resultó, en parte, de la imposición de un estado colonial patriarcal. Para las mujeres, la colonización fue un proceso dual de inferiorización racial y subordinación de género." (Lugones, 2014, Pp. 28).

Para Carneiro (2002), os corpos femininos foram tomados como símbolos de conquista em situações de colonização, a vitória de um grupo se concretiza no controle e violação das mulheres do grupo oponente. Essa perspectiva objetificante é denunciada por Lugones (2014) como um advento que naturalizamos, mas que de fato não se identificava em algumas sociedades, entre elas a yorubá, onde o candomblé é uma religião de grande representatividade e que partilha de itans no qual as mulheres desempenham funções que transcendem a maternidade e cujos corpos não são violados, seja sexualmente ou institucionalmente, como demonstração da superioridade masculina. A imposição dessa lógica onde as mulheres são insti- tucionalmente consideradas não humanas se consolida através de iniciativas repressivas e violentas, mas principalmente a partir da produção de significantes degradantes sobre elas.

Sobre esse aspecto, Lugones (2014) aponta que o sistema de gênero colonial/moderno se organiza num lado visível/claro e um lado invisível/escuro. $\mathrm{O}$ primeiro seria o conjunto de formulações que naturalizam a díade homem-mulher e naturaliza aspectos socialmente identificados como próprios de cada gênero. Passividade sexual, infantilização, submissão e abnegação são características associadas a mulher, tendo como modelo a mulher branca que seria frágil e delicada. Essa definição excluí mulheres não brancas do que seria a categoria mulher, mas efetivamente também produz desumanização sobre os corpos das mulheres brancas:

Pero tan importante como su función reproductora de la propiedad y la raza es que las mujeres burguesas blancas sean excluidas de la esfera de la autoridad colectiva, de la producción del conocimiento, y de casi toda posibilidad de control sobre los medios de producción. La supuesta y socialmente construida debilidad de sus cuerpos $y$ de sus mentes cumplen un papel importante en la reducción y reclusión de las mujeres burguesas blancas con respecto a la mayoría de los dominios de la vida; de la existencia humana. El sistema de género es heterosexualista, ya que la heterosexualidad permea el control patriarcal y racializado sobre la producción, en la que se incluye la producción del conocimiento, y sobre la autoridad colectiva. Entre los hombres y las mujeres burgueses blancos, la heterosexualidad es, a la vez, compulsiva y perversa ya que provoca una violación significativa de los poderes y de los derechos de las mujeres burguesas, y sirve para reproducir el control sobre la producción. Las mujeres burguesas blancas son circunscriptas en esta reducción de sus personas y poderes a través del acceso sexual obligatorio." (Lugones, 2014, p. 41).

O lado oculto/oscuro se manifesta pela violência extrema, pela animalização dos corpos não brancos, pela exploração extrema do seu sexo pelos colonizadores brancos, das suas capacidades laborais, do extermínio de suas produções intelectuais, culturais e dos seus corpos impondo-lhes torturas, estupro, vio- 
lência e até mesmo morte (Lugones, 2014). A dominação das mulheres não brancas passou pela violência e pelo convencimento de sua inferioridade baseada na sua anatomia. Nesse sentido Lugones (2014) vai defender que o status da mulher branca europeia era inferior aos de fêmeas de sociedades que não se organizavam a partir do binarismo de gênero antes da colonização. Isso se daria pelo fato de que as mulheres brancas muitas vezes acreditavam no seu lugar de suposto privilégio como senhoras, mães, esposas legítimas. Estavam alheias das correntes que as mantinham cativas. Não seriam esses recursos efetivos na manutenção de uma hierarquia entre mulheres que professam, reproduzem e defendem a maternidade como fonte de glória e abnegação feminina, desconsiderando a distinção que esse cargo lhes confere na lógica moralista do patriarcado?

A posição de autoridade parcial e condicionada que as mulheres brancas ocupam no sistema de gênero colonial/moderno lhes conferia uma não percepção da opressão como uma estrutura. Como apontam hooks Hooks Brah, Sandoval e Anzaldúa (2004), ao vivenciarem violências esparsas, simbólicas e não extremas, as mulheres podem acreditar que o que vivenciam é uma desigualdade de oportunidades, podendo rejeitar a ideia de estar oprimida já que enxergam os benefícios que o Estado liberal e patriarcal lhes confere. A maternidade, assim, pode ser considerada uma produção visível/clara do sistema de gênero colonial/moderno, visto que ela não outorga às mulheres a condição de sujeito, mas as diferencia entre si, produzindo uma hierarquia que tem como modelo inatingível a mãe virgem do salvador e cuja distinção só é efetiva entre outras mulheres e crianças. A maternidade não traz uma mudança do status social das mulheres no sistema de gênero colonial/moderno. Ainda que discursivamente se produza uma ode elogiosa e homogênea de exaltação a mulher-mãe, efetivamente ela sofre com o preterimento no mercado de trabalho, no mercado afetivo e em redes de socialização.

A centralidade da maternidade na vida da mulher é argumento para que se excluam as mães de espaços públicos. Por outro lado, o interesse das mulheres nos espaços públicos não é aceito como um argumento válido para recusar a maternidade. Do espaço público também se excluem as mulheres que não são mães porque sua recusa produz suspeição e deslegitimação de suas condutas. É à interlocução do privado com o público que a oração da Virgem Maria e o itan sobre
Oxum se referem. O que se passa com essas duas figuras femininas ligadas à maternidade e à reprodução é a representação da máxima feminista o pessoal é político. A maternidade, não é uma opção pessoal das mulheres, já que é uma instituição imposta, reproduzida e legitimada pelas religiões monoteístas, pelo Estado, pela medicina, pelo direito e pela Psicologia

[] a produção científica mantém a reprodução do pensamento social dominante sobre a maternidade ser um ideal a ser alcançado pela mulher para se realizar. Pensamento esse embrenhado em mitos e ideias machistas sobre a mulher e o feminino, e que impactam diretamente em como a não-maternidade é discutida. Verificamos, nos dados dos estudos analisados, a manutenção da perspectiva de que a maternidade é uma normativa na vida das mulheres, que permanece regida por valores morais e culturais socialmente instituídos, baseados em aspectos biológicos, religiosos e de controle da sexualidade e do corpo (re) produtivo feminino. A mensagem, de um modo geral, é a de que "não é proibido não ser mãe", porém, fica claro que as consequências disso são culpa, estigma social e sensação de incompletude. É com base nesse contexto que a mulher ainda hoje precisa fazer suas escolhas e sustentar seus planos de futuro pessoal e de relações afetivas." (Trindade, Coutinho, \& Cortez, 2016, p. 161).

Ao refletir sobre os processos de autoidentificação auto identificação e autoavaliação auto avaliação de mulheres negras norte-americanas, Collins (2016) aponta que ao desmistificarem o ideal de feminino passivo e valorizarem a assertividade e outras qualidades que rompem com os estereótipos negativos produzidos sobre elas, as mulheres negras conseguem fissurar o conteúdo das imagens controladoras que lhes são impostas. O processo de resistência pode implicar na ruptura com o que é violentamente previsto como destino ancorado nos corpos. Para Lugones (2014), no caso das mulheres latinas americanas, esses destinos consistem na animalização de mulheres negras e indígenas, lidas como fêmeas selvagens, sem marcas de feminilidade e no caso das mulheres brancas foi imposta a infantilização e a associação com animais domésticos. Essa leitura aparece no relato de Nancy White, mulher negra norte-americana, ao ser entrevistada aos 73 anos por John Gwaltney: 
"Minha mãe costumava dizer que a mulher negra é a mula do homem branco e que a mulher branca é o seu cachorro. Agora, ela disse isso para dizer o seguinte: nós fazemos o trabalho pesado e apanhamos, quer façamos um bom trabalho ou não. Mas a mulher branca está mais próxima do patrão, e ele faz um carinho em sua cabeça e a deixa dormir dentro de casa, mas não vai tratar nenhuma das duas como se estivesse lidando com uma pessoa. [] bem, você sabe que nenhuma mulher é cachorro ou mula, mas se as pessoas continuarem fazendo você se sentir dessa forma, se você não tiver autonomia de pensamento, você pode começar a deixar que te digam o que você é" (Gwaltney apud Collins, 2016, p. 103, 106).

White identifica que as imagens controladoras que operam sobre as mulheres são do mesmo modelo, diferindo de conteúdo e intensidade, mas não de forma, por isso, por mais que a curto prazo as mulheres negras possam ter benefícios em se aproximar da desumanização direcionada às mulheres brancas, a longo prazo a condição de cativeiro continuaria sendo a mesma (Collins, 2016).

Quais as resistências possíveis diante disso? Recusar a maternidade em um contexto onde ela nos transcende de importância e limita nossas potencialidades é resistir? A defesa da individualidade e da legitimidade da escolha de mulheres que não serão mães é uma pauta para o feminismo decolonial? Redefinir a identidade, as atribuições e os fins para os quais nossas existências se justificam, para além da maternidade, é uma estratégia de descolonizar nossos corpos? No itan apresentado, essa possibilidade se materializa. $\mathrm{O}$ reconhecimento de si possibilita que a figura feminina não se submeta à necessidade ou desejo masculino de descendência ou de fertilidade no mundo. $\mathrm{O}$ que os Orixás masculinos desejam, demandam ou precisam não é obrigação de Oxum. Ser mãe não a faz complacente ou abnegada. Seu poder não é inferior, nem ela se eximirá de se fazer respeitar e ouvir num espaço político de decisão. A maternidade não a faz tenra ou dócil; nem tampouco a fecundidade é um preço que ela aceite pagar pelo respeito dos orixás masculinos. Apesar de ser uma ayabá - termo que originalmente significa Mãe Rainha - e ser considerada a Orixá que propicia a maternidade, Oxum é largamente conhecida por características distintas das que o cristianismo associou às mães. Vaidade, diplomacia, ciúme, sabedoria, beleza e amor são considerados aspectos significativos na composição da divindade yorubá. O seu maior título, Yalodê, é conquistado quando ela se rebela contra uma ordem que a diminuía e torna rios, plantações e mulheres inférteis.

Referências de figuras femininas que não estão ligadas à maternidade são raras, o que torna essa possibilidade muitas vezes ininteligível. A deslegitimação da escolha pela não maternidade é uma experiência recorrente e muitas vezes supõe que as mulheres irão aceitar seu destino ao encontrarem um homem a quem elas queiram dar um filho. Esse encontro com o espermatozoide mágico, como denominaram Anzorena e Yañez (2013), parte do pressuposto de que as mulheres estão alheias a maternidade até que essa possibilidade seja apresentada por uma figura masculina, o que não é relatado por quem toma essa decisão. As mulheres são inseridas na instituição da maternidade por suas próprias mães e são socializadas com conteúdos discursivos que exaltam as mães como única figura feminina confiável; ao mesmo tempo que não se reconhece a exploração e violência física e mental vivida, tal qual é prevista no sistema de gênero colonial/moderno.

A ausência de destinos possíveis para as mulheres, além da maternidade acarreta o questionamento sobre a presumida liberdade de escolha para nossas capacidades reprodutivas. Como a reivindicação do lugar de indivíduo para as mulheres é apontado como falha de caráter que desvia mães em potencial de seus caminhos? Como não causa estranheza, para não falar literalmente em indignação que nossas vidas, que potencialidades e existências sejam resumidas à possiblidade de produção de outrem? Esses questionamentos fazem pensar que a possibilidade de uma existência sem filhos precisa ser retomada como uma bandeira do feminismo decolonial latino--americano. Repensar a maternidade é um caminho para repensar como a ficção de gênero e raça continua produzindo verdades totais sobre nossos corpos e impondo desvalorização de outras experiências, de outros modelos e de outras mulheres.

Recuperando a distinção de como corpo e a fertilidade são operacionalizados para estabelecer relação entre mulheres no itan de Oxum e na narração da experiência descrita nos anúncios de concepção de Maria, a maternidade não é a experiência que destaca Oxum entre as mulheres, pelo contrário, é a negação estratégica dessa possibilidade que a faz 
alcançar um posto de respeito entre os Orixás masculinos não apenas para si, como também exige que as outras ayabás ${ }^{5}$ nas decisões. Ao retirar seu axé do mundo, Oxum não o faz por si, exclusivamente, mas também pelas outras ayabás excluídas pelo mesmo argumento de que as mulheres não são necessárias. Entre nós latino-americanas, recusar a maternidade pode ser uma possibilidade de retomada dos nossos corpos, da nossa sexualidade - acorrentada à heterossexualidade compulsória como primazia da reprodução - da nossa capacidade reprodutiva e dos nossos destinos.

"Nuestras resistencias al mandato de la maternidad heteropatriarcal son formas de transgresión y rebeldía que se materializan en nuestros cuerpos, tal como plasmamos en los relatos que presentamos. Creemos que es necesario ubicar la elección de no gestar ni parir como una opción real en el movimiento y la teoría feminista, como uma condición necesaria para la existencia de una maternidad voluntaria y plena. Del mismo modo que sin derecho al aborto no hay derecho a la maternidad voluntaria, tampoco lo hay sin derecho a la "no-maternidad" como elección y no como destino trágico." (Anzorena, \& Yañes, 2013, Pp. 223).

Faz-se necessário destituir a maternidade tanto do endeusamento de que tudo suporta - afinal, de que adianta o paraíso se for para padecer? - como da demonização que a ciência tão recorrentemente usa com o intuito de reificar a culpa das mulheres - mães psicotizantes, mães suficientemente boas, estéreis, disfuncionais, sujeitos faltantes. É preciso que falemos mais sobre a maternidade e menos sobre as mulheres que precisam vivê-la. Desconstruir o binarismo a que foi discursivamente reduzido o continuum de experiências que cercam a reprodução, desnaturalizar os imperativos que atrelam as mulheres à prole $\mathrm{e}$ considerar a recusa pela maternidade como escolha legítima, tanto pessoalmente como politicamente, podem ser caminhos para anular a ideia de que nossa existência precisa de redenção por uma maçã que foi supostamente roubada em um jardim em que nós nem escolhemos estar, nem precisamos permanecer.

\section{Referências}

Anzorena, C., \& Yáñez, S. (2013). Narrar la ambivalencia desde el cuerpo: diálogo sobre nuestras propias experiencias en torno a la "no-maternidad". Investigaciones Feministas, 4, 221-239. https://doi.org/10.5209/rev_ INFE.2013.v4.43890

Articulação de Organizações de Mulheres Negras Brasileiras. (2012). Saúde da mulher negra: Guia para a defesa dos direitos das mulheres negras. Porto Alegre, RS; o autor.

Badinter, E. (2011). O conflito: A mulher e a mãe. Rio de Janeiro, RJ: Record

Beauvoir, S. (1980). O segundo sexo: A experiência vivida (Vol. 2). Rio de Janeiro, RJ: Nova Fronteira.

Carby, H. (1989) Reconstructing womanhood: The emergence of the Afro-American woman novelist. New York, NY: Oxford University Press.

Carneiro, S. (2002). Gênero e raça. In C. Bruschini, \& S. G. Unbehaum (Orgs.), Gênero, democracia e sociedade brasileira (pp. 169-193). São Paulo, SP: Fundação Carlos Chagas.

Collins, P. H. (2016). Aprendendo com a outsider within: a significação sociológica do pensamento feminista negro. Sociedade e Estado, 31(1), 99-127. http://dx.doi.org/10.1590/S0102-69922016000100006

Damasco, M. S., Maio, M. C., \& Monteiro, S. (2012). Feminismo negro: Raça, identidade e saúde reprodutiva no Brasil (1975-1993). Revista Estudos Feministas, 20(1), 133-151. https:// doi.org/10.1590/S0104-026X2012000100008

Del Priore, M. L. M. (1994). A árvore e o fruto: Um breve ensaio sobre o aborto na história. Revista Bioética, 2(1), 43-51.

Dimen, M. (1997). Poder, sexualidade e intimidade. In A. M. Jaggar, \& S R. Bordo (Eds.), Género, corpo, conhecimento (B. L. Freitas, trad.). Rio de Janeiro, RJ: Record: Rosa dos Tempos.

${ }^{5} \mathrm{O}$ termo originalmente se referiria as orixás das águas, Nanã, Yemanjá e Oxum. Na tradição do candomblé no Brasil, o termo abrange todas as orixás femininas. 
Gonzalez, L. (1983). Racismo e sexismo na cultura brasileira. Ciências Sociais Hoje, 2, 223-244.

Hanisch, C. (1971). “The personal is political”. In J. Agel, The radical therapist (pp. 152-157). New York, NY: Ballatine Books.

Hooks, B., A. Brah, C. Sandoval, \& G. Anzaldúa. (2004). Otras inapropriables: Feminismos desde las fronteras. Madrid: Traficantes de Sueños.

Jimenez-Lucena, I. (2014). In: Mignolo, W., Género y decolonialidad. (pp. 43-64) Buenos Aires: Del Signo.

Lei No 9.263, de 12 de janeiro de1996. Regula o $\$ 7^{\circ}$ do art. 226 da Constituição Federal, que trata do planejamento familiar, estabelece penalidades e dá outras providências. Diário Oficial da União, 15 de janeiro de 1996.

Lerner, G. (1990). El origen del patriarcado In G. Lerner, La creación del patriarcado pp. 310-330). Barcelona: Critica. Lugones, M. (2014). Colonialidad y género. In W. Mignolo, Género y decolonialidad. (p. 13-42) Buenos Aires: Del Signo.

Machado, L. Z. (2010). O impacto social das narrativas biológicas, jurídicas e religiosas sobre o aborto In L. Z. Machado, Feminismo em movimento (pp. 135-198.) São Paulo, SP: Francis.

Mayorga, C. (2011). Brasil e a questão racial: Entre mitos, ideologias e lutas. In B. Medrado, W. Galindo (Orgs.), Psicologia social e seus movimentos: 30 anos de ABRAPSO (pp. 71-96). Recife, PE: Abrapso.

Millet, K. (2000). Política sexual. Madrid: Ediciones Cátedra. (Original publicado em 1970).

Mignolo, W., Jimenez-Lucena, I., Lugones, M., \& Tlostanova, M. (2114). Género y decolonialidad. Buenos Aires: Del Signo.

Mott, M. L. B. (1989). Ser mãe: a escrava em face do aborto e do infanticídio. Revista de História, (120), 85-96.

Ruibal, A. M. (2014). Feminismo frente a fundamentalismos religiosos: Mobilização e contramobilização em torno dos direitos reprodutivos na América Latina. Revista Brasileira de Ciência Política, (14), 111-138. https://doi. org/10.1590/0103-33522014140.

Scott, J. W. (1990). Gênero: Uma categoria útil para a análise histórica. Educação e Realidade, 16(2), 5-22.

Swan, T. N. (2007). Meu corpo é um útero? Reflexões sobre procriação e Matenidade. In Stevens, C. (org.), Feminismo e maternidade: Diálogos interdisciplinares (pp. 201-244). Florianópolis, SC: Mulheres.

Trindade, Z. A., Coutinho, S. S. M., \& Cortez, M. B. (2016). Ainda é proibido não ser mãe? A não maternidade tratada nas publicações científicas da Psicologia. In V. Zanello, \& M. Porto, Aborto e (não) desejo de maternidade(s): Questões para a Psicologia (pp. 143-165). Brasília, DF: CFP.

Werneck, J. (2004). O belo ou o puro? Racismo, eugenia e novas (bio)tec-nologias. In A. A. Rptamoa, \& J. Werneck (Eds.), Sob o signo das bios: Vozes críticas da sociedade civil (pp. 49-62). Rio de Janeiro, RJ: E-Papers.

\section{Paula Rita Bacellar Gonzaga}

Professora Assistente da Universidade Federal do Sul da Bahia onde coordena o Programa Integrado de Pesquisa, Extensão e Criação - Janaína Aparecida. Doutoranda em Psicologia Social na Universidade Federal de Minas Gerais e também vinculada ao Núcleo de Ensino, Pesquisa e Extensão - Conexões de Saberes. Mestra em estudos interdisciplinares sobre mulheres, gênero e feminismo- PPGNEIM/Ufba, Teixeira de Freitas - BA. Brasil.

E-mail: paularitagonzaga@gmail.com

(iD) https://orcid.org/0000-0001-7095-5345

\section{Claudia Mayorga}

Doutorado em psicologia social pela universidad complutense de Madri; Professora do departamento de Psicologia e do Programa de pós-graduação em Psicologia da Universidade Federal de Minas GeraisUFMG. Belo Horizonte MG. Brasil.Coordenadora do núcleo de ensino, pesquisa e extensão Conexões de Saberes/UFMG.

E-mail: claudiamayorga@ufmg.br

(iD) https://orcid.org/0000-0003-1728-0726 
Como citar: Gonzaga, P. \& Mayorga, C. (2019). Violências e Instituição Maternidade: uma Reflexão Feminista Decolonial. Psicologia: Ciência e Profissão, 39(n.spe 2), 59-73. https://doi.org/10.1590/1982-3703003225712

How to cite: Gonzaga, P. \& Mayorga, C. (2019). Violence and the Institution of Motherhood: a Decolonial Feminist Reflection. Psicologia: Ciência e Profissão, 39(n.spe 2), 59-73. https://doi.org/10.1590/1982-3703003225712

Cómo citar: Gonzaga, P. \& Mayorga, C. (2019).Violencias y la Institución Maternidad: una Reflexión Feminista Decolonial. Psicologia: Ciência e Profissão, 39(n.spe 2), 59-73. https:// doi.org/10.1590/1982-3703003225712 